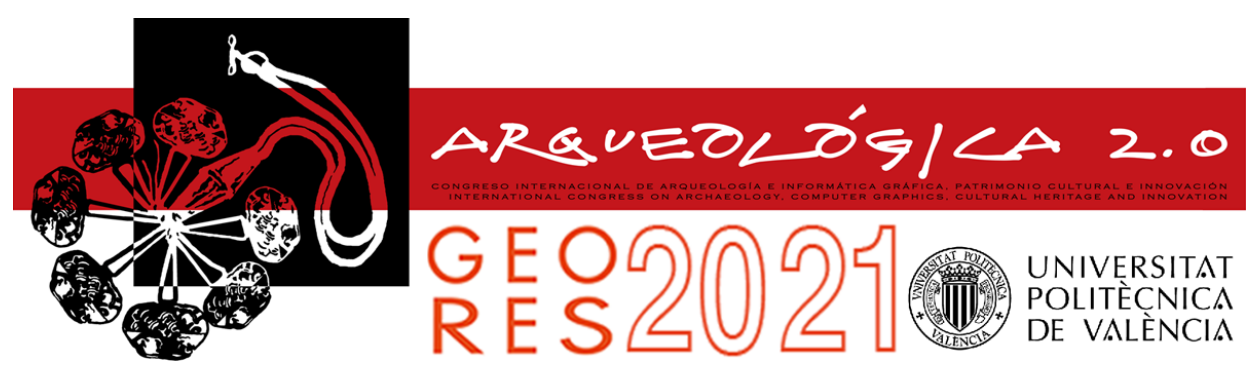

Proceedings of the joint international event $9^{\text {th }}$ ARQUEOLÓGICA

$2.0 \& 3^{\text {rd }}$ GEORES

Valencia (Spain).

26-28 April 2021

\title{
MULTI-SCALE AND MULTI-DOMAIN APPROACHES FOR CULTURAL TERRACED LANDSCAPES
}

\author{
Erica Isabella Parisia, ${ }^{a,}, J^{,}$Jakub Tyc ${ }^{b}$ \\ ${ }^{a}$ Laboratory of Geomatics for Environment and Conservation of Cultural Heritage (GeCo), Department of Civil and Environmental \\ Engineering, University of Florence, Via di S. Marta 3, 50139 Florence, Italy. ericaisabella.parisi@unifi.it \\ ${ }^{\mathrm{b}}$ Digital Architecture and Planning, Institute of Architectural Sciences, Vienna University of Technology, Karlsplatz 13, A-1040 Vienna, \\ Austria. jakub.tyc@tuwien.ac.at
}

\begin{abstract}
:
This contribution reports the activities aiming at multi-domain and multi-scale research applied to cultural terraced landscapes. Terracing and dry-stone walling have been internationally recognized as carriers of cultural values and traditional knowledge. Lamole in Chianti (Italy) has served as a primary case study of terraced vineyards, where interdisciplinary research has been converging for almost a decade. The evolution of multi-sensor data acquisition in different spectral ranges, data-driven modelling, and multi-scalar approaches performed over the years are mentioned, with specific attention to the evaluation of microclimate variations induced by dry-stone walls and how they affect plant growth, ripening, and production. The results already obtained from data processing and analysis are described, although the work is still progressing. The ongoing and planned future research are reported for developing methodologies to understand the parameters that are critical for the effective restoration and functioning of the dry-stone walled vineyards and construct performance-oriented design strategies to enable knowledge-based design processes.
\end{abstract}

Keywords: terracing, dry-stone walls, cultural landscapes, microclimate, thermal infrared, photogrammetry

\section{Terraced landscapes}

Terracing is considered one of the most evident anthropogenic footprints on the landscape. This traditional agro-hydraulic system represents a longstanding and intimate relationship between humankind and nature. Some of these "Cultural landscape" sites, with peculiar value, are protected by UNESCO and inscribed in the World Heritage List (UNESCO, 1979), from rice terraces in China and Philippines to the typical Italian terraced landscapes (Costiera Amalfitana and Portovenere, Cinque Terre). Another international recognition of the specific agricultural value of terraces has been given by FAO - Globally Important Agricultural Heritage Systems (GIAHS), for recovering traditional knowledge, farm resilience, food security, cultural identity, agrobiodiversity, and landscape peculiarity criteria. Amongst the overall protected agricultural areas, at least $17 / 50$ sites are terraced landscapes (Varotto, Bonardi, \& Tarolli, 2019), from Andean terraced agriculture (Peru) to the olive groves of the slopes between Assisi and Spoleto (Italy) (FAO-GIAHS, 2002).

Dry-stone walls are strictly connected to terraces since they represent structural elements and retaining slope systems. The "Art of dry-stone walling, knowledge and techniques" was inscribed in the UNESCO
Representative List of the Intangible Cultural Heritage of Humanity in 2018 (Intergovernmental Committee, 2018).

The combined presence of terraces and dry-stone walls strongly influences and shapes steep hillsides and the environment. The main functions of terraces (Agnoletti, Conti, Frezza, Monti, \& Santoro, 2015) are widely recognised as:

- Control of water runoff and storage.

- Prevention of erosion phenomena.

- Improvement of soil fertility and productivity.

- Increase food quality and security.

- Foster agrobiodiversity.

- Enhance landscape complexity.

- Face climate changes.

The natural hydrogeological processes, mitigated by these artificial systems, tend to reactivate because of the lack of active terracing conservation. The main issues triggering slope dynamics may be ascribed to land abandonment by the farmers, inappropriate maintenance of terraces, dry-stone walls and drainage systems, and to the lack of shared regulations for their management.

`Corresponding Author: Erica Isabella Parisi, ericaisabella.parisi@unifi.it 


\section{The case study of Lamole}

The Italian territory is made up for $77 \%$ by mountains and hills, thus terracing is the primary form of adaptation to the adverse environmental conditions for polyculture cultivation, mainly olive groves and vineyards (Agnoletti, Conti, Frezza, Monti, \& Santoro, 2015) The typical Tuscan landscape represents a complex resource, with a cultural, historical, environmental, social, and economic value, fundamental for rural areas' identity and development (Sereni, 1991).

The Chianti Classico area is characterized by a synergy of natural and anthropic structures, and it represents a remarkable example of terraced vineyards landscape. Lamole is an ancient site for wine production, dating back to Roman times and with a prestigious history related to the Medici family. Its position at a medium altitude of 600 m MSL (Mean Sea Level) has fostered the use of bench terraces to create horizontal surfaces that strongly reshaped the steep slopes of the hills for agriculture.

These traditional features have been progressively recognised, from a cultural, social, and economic, point of view, in recent years. In fact, in 2018 Lamole was included in the Rural Historic Landscape Catalogue of the Italian Ministry of Agricultural, Food, Forestry Policies (Ministerial Decree, 2018). Moreover, the Italian interministerial decree of June 2020 (Inter-ministerial Decree, 2020) defines and recognizes heroic and historical vineyards, as a further step in the valorisation of traditional and sustainable agricultural practices.

Over the years, both Lamole's terraces and dry-stone walls have been suffering abandonment, in favour of more industrial systems, and degradation processes such as deformations, bulging and collapses. Recently, a process of recovery and conservation of past traditions and ancient structures is being carried out by local farmers.

In particular, the terracing and dry-stone walls recovery, restoration and conservation activities performed by $\mathrm{Mr}$. Paolo Socci (Fattoria di Lamole) since 2003 have provided useful sites for the tests, thus allowing a productive and enduring collaboration throughout the years.

Four bench terraced vineyards have been surveyed and analysed since 2016: Grospoli I, Grospoli II (Fig. 1), Castello and a newly constructed vineyard. An overview of the Grospoli area is shown in Figure 2. Grospoli I and II vineyards are located at altitudes ranging from 550 to 630 meters on the west-facing slopes in near proximity to the centre of Lamole. The Castello vineyard is located at altitudes from 510 to 540 meters, mainly on the northeastfacing slope (see Fig. 3). The name of the vineyard comes from the adjacent settlement - Castello di Lamole (marked orange in Figure 3).

\section{Research on the field}

Lamole has been a suitable case study for multi-domain and multi-scale approaches, aiming to address practical problems, in strict collaboration with the local farmers, building up on their experience and responding to their needs.

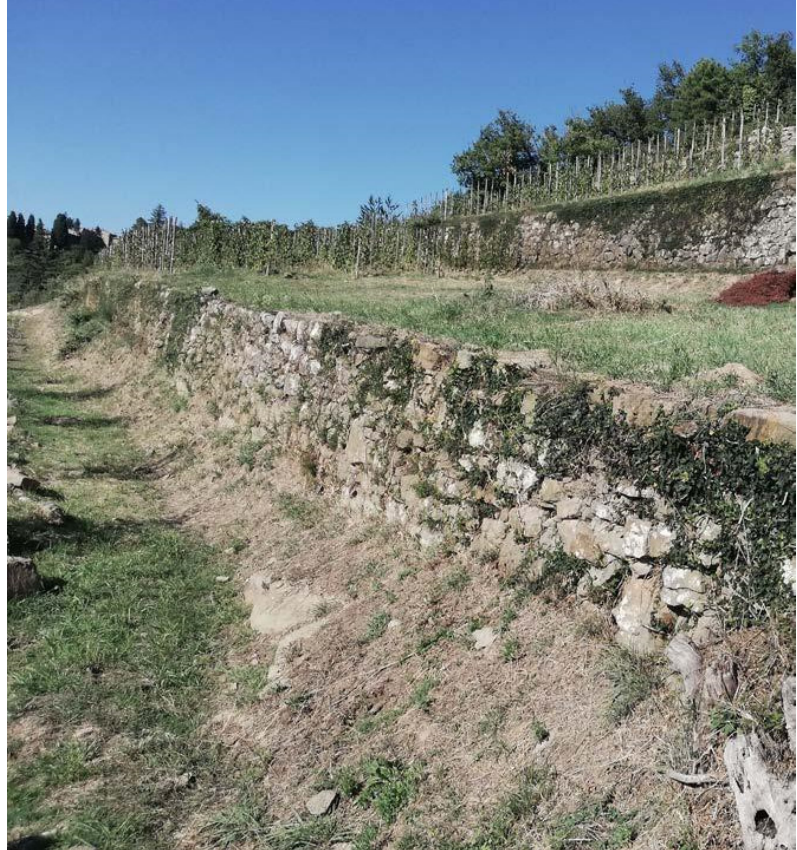

Figure 1: Dry-stone walls and terraces in the Grospoli II vineyard. Height of the dry-stone walls varies throughout the vineyard, as well as the distribution of the wine plants on each terrace.

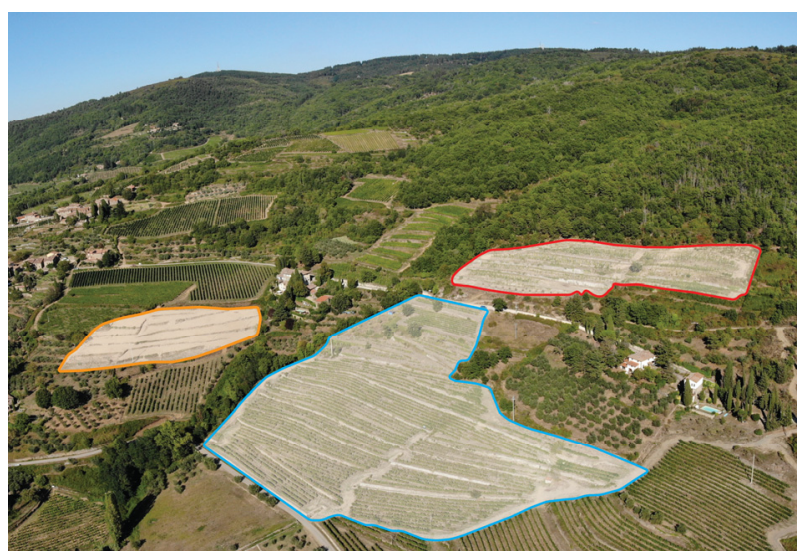

Figure 2: The Grospoli I vineyard (marked blue) was surveyed in 2017 (Tucci et al., 2019), Grospoli II vineyard (marked red) was analysed in 2019 as a part of a Master Thesis in

Architecture (Gambini, Nassi, \& Tesi, 2020) and surveyed in the TIR range in 2020 . The vineyard marked in orange was newly constructed in 2020; an initial survey was conducted at that time.

Several research groups, belonging to different disciplines, have been studying terraced-related phenomena for almost a decade in Lamole (Agnoletti, 2013). Experts in the field of agronomy, hydraulics, landscape architecture, civil and environmental engineering, and geomatics, have joined their efforts for the combined study of degradation mechanisms, like soil erosion, slope failure processes, water flows pathways, which can cause damage to retaining walls, terracing failures and trigger landslides (Preti, Tarolli, Dani, Calligaro, \& Prosdocimi, 2013; Tarolli, Preti, \& Romano, 2014; Tarolli et al., 2015; Preti, Errico, Caruso, Dani, \& Guastini, 2018; Preti, et al., 2018; Varotto, Bonardi, \& Tarolli, 2019; Socci, Errico, Castelli, Penna, \& Preti, 2019). 
One aspect that has been foregrounding since 2015 is the study of temperature variations induced by terraces and dry-stone walls and how these affects vine growth and ripening, influencing the final quality of the produced wine. Multi-sensor aerial and ground-based data acquisition have been performed to study the effect of microclimate on a local scale, and data-driven models have been constructed to accommodate the diverse disciplinary perspectives of the participants.

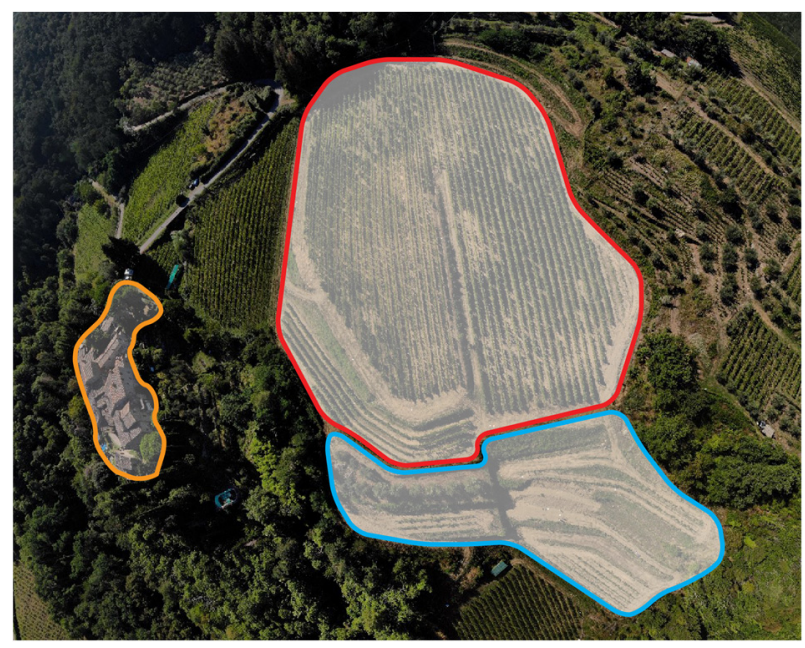

Figure 3: The Castello vineyard has been surveyed in September 2020. The terraced part (marked blue) is located at the lowest part of the vineyard and facing northeast. Nonterraced part (marked red) is constructed on a continuous, moderate slope facing north (rows of wine plants running in the north-south direction). In orange the Castello small hamlet.

\subsection{The adopted methodologies}

Different technologies and methodologies have been adopted for thermal behaviour evaluations. Details on the Unmanned Aerial Vehicles (UAV) and sensors specifics are extensively reported in Tables 1-3.

Tables 1-3 show specifications of methodologies, instruments, and sensors used for field-tests from 2017 to 2020. The subdivision is made by year and vineyard, describing the adopted methodologies (ground- or aerialbased), the UAV platforms, and the characteristics of the sensors. Also, radiometric, spatial, and temporal resolutions are reported for each survey. For spatial resolution GSD is considered for $3 D$ outputs and projections (orthomosaics); for thermal sensors IFOV (Instantaneous Field of View) at $1 \mathrm{~m}$ is used for comparison.

A first approach involved the use of fixed weather stations on the field for environmental parameter monitoring (like air temperature, relative humidity, wind speed, etc.). These sensors were installed and controlled by the Research Centre for Architecture and Tectonics (RCAT) of the Oslo School of Architecture and Design from 2016 to 2017.

A combination of ground-based and aerial-based data acquisition in the visible (VIS) and Thermal-InfraRed (TIR) ranges have being performed since 2017 . A methodology that combines aerial photogrammetry and multi-sensor imaging was tested in 2017, under the coordination of the University of Florence (Tucci et al., 2019; Parisi, Suma, Güleç Korumaz, Rosina, \& Tucci, 2019). The study allowed the production of $3 D$ models from aerial-based
(UAV) photogrammetry of the Grospoli I vineyard (marked blue in Fig. 2), both in the VIS and TIR spectral range.

Table 1: 2017 field test: Grospoli I.

\begin{tabular}{|c|c|c|}
\hline Methodology & Ground-based & Aerial-based \\
\hline Photogrammetry & & $\mathrm{x}$ \\
\hline Thermal imaging & & $\mathrm{x}$ \\
\hline Specifications & $R G B$ & TIR \\
\hline UAV & $\begin{array}{c}\text { DJI Phantom } 4 \\
\text { Pro }\end{array}$ & $\begin{array}{l}\text { customized } \\
\text { hexacopter }\end{array}$ \\
\hline Sensor & $\begin{array}{l}\text { DJI FC6310 1" } \\
\text { CMOS }\end{array}$ & $\begin{array}{l}\text { OPTRIS PI450 } \\
\text { FPA, uncooled }\end{array}$ \\
\hline $\begin{array}{l}\text { Optical resolution } \\
\text { (pix) }\end{array}$ & $5472 \times 3648$ & $382 \times 288$ \\
\hline $\begin{array}{l}\text { Thermal sensitivity } \\
\left(\text { at } 30^{\circ} \mathrm{C}\right)\end{array}$ & & $0.04^{\circ} \mathrm{C}$ \\
\hline Spectral range & Visible & $8-14 \mu m$ \\
\hline Temporal resolution & $\begin{array}{l}\text { Once/day on } \\
\text { Sept. 7, } 2017\end{array}$ & $\begin{array}{c}\text { Twice/day } \\
(08: 50 / 15: 00)\end{array}$ \\
\hline $\begin{array}{l}\text { Spatial resolution } \\
\text { (GSD) }\end{array}$ & $2 \mathrm{~cm} / \mathrm{pix}$ & $12 \mathrm{~cm} / \mathrm{pix}$ \\
\hline
\end{tabular}

Table 2: 2019 field test: Grospoli II.

\begin{tabular}{c|c|c} 
Methodology & Ground-based & Aerial-based \\
\hline Photogrammetry & $\mathrm{x}$ & $\mathrm{x}$ \\
Thermal imaging & $\mathrm{x}$ &
\end{tabular}

\begin{tabular}{|c|c|c|}
\hline Specifications & $R G B$ & TIR \\
\hline UAV & $\begin{array}{c}\text { DJI Phantom } 4 \\
\text { Pro }\end{array}$ & \\
\hline UAV sensor & $\begin{array}{l}\text { DJI FC6310 1" } \\
\text { CMOS }\end{array}$ & \\
\hline Ground sensors & $\begin{array}{l}\text { Nikon D3300 } \\
\text { CMOS }\end{array}$ & $\begin{array}{c}\text { FLIR B360 } \\
\text { FPA, uncooled }\end{array}$ \\
\hline $\begin{array}{l}\text { Optical resolution } \\
\text { UAV (pix) }\end{array}$ & $5472 \times 3648$ & \\
\hline $\begin{array}{l}\text { Optical resolution } \\
\text { Ground sensors } \\
\text { (pix) }\end{array}$ & $6000 \times 4000$ & $320 \times 240$ \\
\hline $\begin{array}{l}\text { Thermal sensitivity } \\
\quad\left(\text { at } 30^{\circ} \mathrm{C}\right)\end{array}$ & & $<0.05^{\circ} \mathrm{C}$ \\
\hline Spectral range & Visible & $7.5-13 \mu \mathrm{m}$ \\
\hline Temporal resolution & $\begin{array}{l}\text { Once/day on } \\
\text { Sept. 13, } 2019\end{array}$ & $\begin{array}{c}\text { Every } 2 \text { hours } \\
\text { /day }\end{array}$ \\
\hline UAV GSD & $1.5 \mathrm{~cm} / \mathrm{pix}$ & \\
\hline $\begin{array}{l}\text { Ground sensors } \\
\text { GSD/IFOV }\end{array}$ & $1 \mathrm{~mm} / \mathrm{pix}$ & $\begin{array}{l}\text { IFOV } 1.4 \mathrm{~mm}^{2} \\
\text { at } 1 \mathrm{~m}\end{array}$ \\
\hline
\end{tabular}

A common photogrammetry survey was performed to reconstruct the geometry of the vineyard with a DJI Phantom 4.0 Pro drone, equipped with an RGB digital camera (for further details see Tables 1-3). A customized aircraft was used for TIR radiometric survey, with two different flights (in the morning and in the afternoon). 
The main challenge was to set up a procedure for frame extraction from the thermal radiometric videos, maintaining the thermal information and obtaining suitable images for the photogrammetric process. The completed procedure is reported in Tucci et al. (2019). The produced orthomosaics were compared thanks to a common reference system provided by GNSS measurements of special targets, covered in aluminium foil, visible also in the TIR. The spatial resolution (given by Ground Sample Distance - GSD in Tables 1-3) of the orthomosaics was considerably different because of different sensors size for VIS and TIR.

Table 3: 2020 field test: Grospoli II / Castello.

\begin{tabular}{|c|c|c|}
\hline Methodology & $\begin{array}{l}\text { Ground- } \\
\text { based }\end{array}$ & Aerial-based \\
\hline Photogrammetry & & $x$ \\
\hline Thermal imaging & $x$ & $x$ \\
\hline Specifications & $R G B$ & $T I R$ \\
\hline UAV & \multicolumn{2}{|c|}{ DJI Mavic 2 Enterprise dual } \\
\hline UAV sensor & \multirow[t]{3}{*}{$\begin{array}{l}\text { M2ED 1/2.3" } \\
\text { CMOS }\end{array}$} & $\begin{array}{l}\text { M2ED FPA, } \\
\text { uncooled }\end{array}$ \\
\hline Thermal sensor & & FLIR SC620 \\
\hline & & $\begin{array}{l}\text { WIC } 336 \text { FPA, } \\
\text { uncooled }\end{array}$ \\
\hline $\begin{array}{l}\text { Optical resolution } \\
\text { UAV (pix) }\end{array}$ & \multirow[t]{6}{*}{$4056 \times 3040$} & $160 \times 120$ \\
\hline Optical resolution & & FLIR $640 \times 480$ \\
\hline $\begin{array}{l}\text { Thermal cameras } \\
\text { (pix) }\end{array}$ & & WIC $336 \times 256$ \\
\hline Thermal sensitivity & & $\mathrm{UAV}<0.05^{\circ} \mathrm{C}$ \\
\hline (at $\left.30^{\circ} \mathrm{C}\right)$ & & FLIR $0.04^{\circ} \mathrm{C}$ \\
\hline & & WIC $\leq 0.03^{\circ} \mathrm{C}$ \\
\hline Spectral range UAV & \multirow[t]{2}{*}{ Visible } & $8-14 \mu m$ \\
\hline $\begin{array}{l}\text { Spectral range } \\
\text { Thermal cameras }\end{array}$ & & $\begin{array}{c}\text { FLIR } 8-14 \mu \mathrm{m} \\
\text { WIC } 7.5-13.5 \mu \mathrm{m}\end{array}$ \\
\hline $\begin{array}{c}\text { Temporal resolution } \\
\text { UAV }\end{array}$ & \multicolumn{2}{|c|}{$\begin{array}{l}\text { Every } 3 \text { hours/day on Sept. 5-8, } \\
2020\end{array}$} \\
\hline $\begin{array}{l}\text { Temporal resolution } \\
\text { Thermal cameras }\end{array}$ & \multirow{3}{*}{$1 \mathrm{~cm} / \mathrm{px}$} & $\begin{array}{l}\text { FLIR } 10 \mathrm{~min} / \text { day } \\
\text { WIC } 5 \mathrm{~min} / \text { day }\end{array}$ \\
\hline UAV GSD & & N.A. \\
\hline $\begin{array}{l}\text { Ground sensors } \\
\text { GSD/IFOV }\end{array}$ & & $\begin{array}{l}\text { FLIR } 0.6 \mathrm{~mm}^{2} \text { at } 1 \mathrm{~m} \\
\text { WIC (IFOV) } 1.3 \mathrm{~mm}^{2} \\
\text { at } 1 \mathrm{~m}\end{array}$ \\
\hline
\end{tabular}

Evaluations on a different scale were performed in 2019, with a ground-based experimental setup to record the daily surface temperature variation of both sides of the closest grapevine rows to the wall. A new vineyard (Grospoli II, marked red in Figure 2) was used as case study and spatially reconstructed in $3 D$ by UAV photogrammetry. A new experiment with a ground thermal camera (FLIR B360) was set up for monitoring daily temperature variations of dry-stone walls and the closest vine rows with high spatial and temporal resolution (thermal images acquired every two hours for one day as reported in Table 2)). Ground-based photogrammetry was also applied for reconstructing a section of a drystone wall affected by bulging to assess its structural performances (GSD $1 \mathrm{~mm} / \mathrm{px}$ ).

The previous experience was useful to combine, in 2020 surveys, ground-based and aerial-based methodologies to produce spatial data in both VIS and TIR range. The Grospoli II and Castello vineyards were used for data collection. Castello vineyard was also surveyed with aerial photogrammetry to reproduce its georeferenced spatial geometry.

The aerial survey utilized a low-cost UAV (DJI Mavic 2 Enterprise Dual), which includes both RGB and nonradiometric TIR sensors in a stereo setup. Some of the best practices proposed by (Kelly et al., 2019) were applied to derive accurate temperature data with this UAV platform. In addition, the ground-based experimental setup was improved, by using two thermal radiometric cameras (FLIR SC620 and WIC 336) in fixed positions, framing the dry-stone wall and the vines in the closest proximity. Spatial and temporal resolutions (5-10 minutes/day) were further increased to have a more accurate daily monitoring of the thermal behaviour (Table 3 ). All the atmospheric parameters needed for absolute temperature evaluation in thermography, were provided by thermo-hygrometers placed close to the thermal cameras. A validation system was also considered, using contacts sensors (thermocouples) measures on special aluminium reference targets. This experimental setup is considered the last methodological evolution to deliver accurate temperature data in two different scales, from the single plant to entire vineyard.

\subsection{Obtained results}

The methodologies reported in section 4.1 allowed to collect multi-source data analysed with multi-domain approaches. This section mentions some of the results obtained in the past years.

The Research Centre for Architecture and Tectonics (RCAT) at the Oslo School of Architecture and Design applied the research by designing methodology based on the integration of data collected on the field. Master-level students developed speculative projects to learn how to design in highly sensitive environments while preserving the environmental conditions of the terraced vineyards. Weather data collected on-site over two years period was used in the micro-climate simulations, supplemented also by the results of the thermographic survey and by the expert knowledge on the requirements for the growth of vine plants. Such a process required the application of data-driven parametric design processes, incorporating both the datasets, uncommon for architecture and the interdisciplinary knowledge of the collaborators involved.

The tests carried out on the field in 2017 allowed to experiment new approaches for multi-spectral data collection and to set up new methods for data processing and analysis. In particular, the TIR radiometric sensor (OPTRIS PI450) mounted on the UAV was able to acquire only radiometric videos, thus a suitable procedure was created for extracting radiometric images to be used for the photogrammetric reconstruction. The results are two radiometric 3D models and thermal orthomosaics of the Grospoli I vineyard (morning and afternoon), which can be overlayed to the VIS orthophoto of the same area. The measured temperatures are to be considered as relative 
values since it was not possible to insert all the ambient and specific parameters (air temperature, relative humidity, distance, emissivity, reflected temperature) used for absolute readings. A visual interpretation of the thermal behaviour in Figure 4, already suggests that the closest vine rows in respect to the bottom of the dry-stone walls are colder in morning compared to all the other rows, while in the afternoon the thermal equilibrium is reached. Furthermore, a statistical analysis of the associated temperature values, were performed over all the plant rows of the vineyard through GIS to monitor their daily thermal behaviour, the possible influence of the drystone walls, and of solar exposition. The results, extensively reported in Tucci et al. (2019), showed that the main measurable effects on temperature variations are due to solar irradiation and shadowing, although some minor variations were detected. This preliminary research and its promising results drove to further experiments on the topic. The necessity of higher spatial and temporal resolution led then to a multi-scale approach, still ongoing, with ground-based tests coupled with aerial and UAV surveys, further reported in section 4.3.

The multi-scalar approach for studying the terraced landscape of Lamole, was also the research topic of a Master Thesis in Architecture, supervised by the GeCo Lab of the University of Florence in 2019 (Gambini, Nassi, \& Tesi, 2020). The analysis of 3D spatial data, obtained by photogrammetry, of a single dry-stone wall and of a vineyard (Grospoli II), was combined with an extensive study of the land-use changes over decades of the entire area, based on national and regional GIS systems. Abandonment, lack of knowledge on how to maintain and how to design for reconstruction and durability of the terraced vineyards were found to be the biggest threats for the preservation of the historic terraced vineyards. The study included the role of plants in the considered scales, from the changes in the forest coverage, through the analysis of the species distribution in the proximity of the vineyard and the presence of plants on the walls and its relation to the structural stability. The scope of the study was the analysis of the relations between the territory, the landscape, the single vineyard and the dry-stone walls, as inseparable elements that belong to the complexity of a terraced cultural landscape, with the final aim to produce and manage information to preserve such diffuse heritage (Fig. 5).

\subsection{Ongoing and future research}

In 2020, two new terraced vineyards were constructed in Lamole by two winemaker companies who decided to recover pre-existing structures or build new terraces. Supposedly, global climate change influences the ripening processes of the grapes, thus increasing the attractiveness of such high-altitude locations as Lamole. The abovementioned winemakers are looking back at the historic examples of the terraced vineyards to recover the knowledge on how to construct and maintain such agricultural systems. In some cases, historical orthophotographs of Lamole can provide insights on the structure of the terraced vineyards, yet the methods to efficiently support the multi-objective planning processes of the vineyard restoration are to be studied. Interdisciplinary-oriented restoration of the terraced vineyards allows to cultivate steep slopes and, due to enhanced slope stability, mitigates the risks of landslides and vineyard soil erosion. A preliminary photogrammetric survey of the first newly constructed vineyard was carried out in September 2020 (marked orange in Figure 2). This opens the possibility to observe the complete evolution of the terraced vineyard in the upcoming years of surveys.
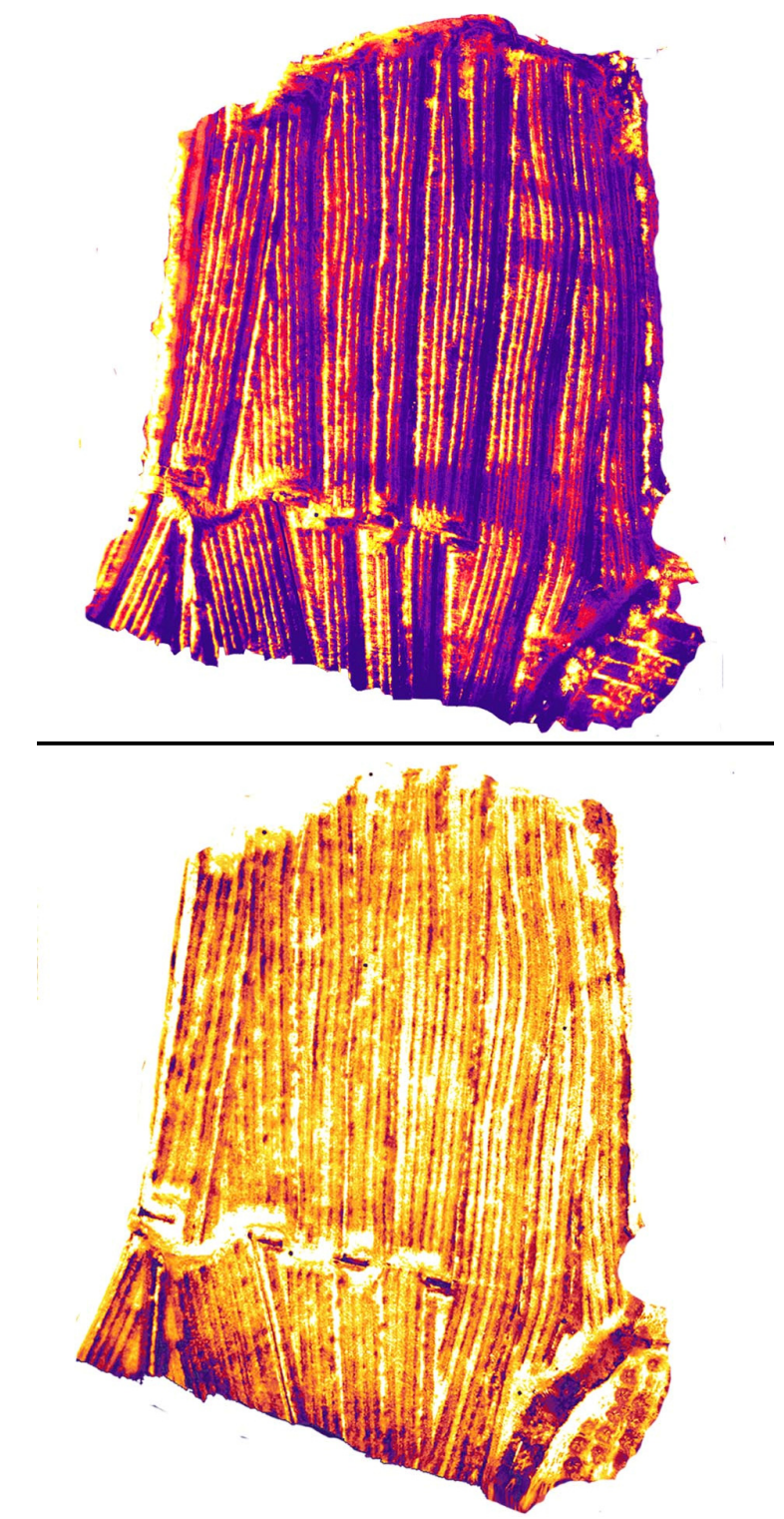

Figure 4: Thermal orthomosaics of the morning UAV photogrammetric flight (top) and of the afternoon (bottom). The daily temperature variation is clearly showed: in the morning (temperature relative range $14.8-18.3^{\circ} \mathrm{C}$ ) shadowing effects cause the dry-stone wall facing rows to be colder than the other rows; in the afternoon (temperature relative range $21-25^{\circ} \mathrm{C}$ ) solar insolation allowed to reach thermal equilibrium.

Acknowledging the importance of the terraced vineyards, this research is developing methodologies to understand the parameters that are critical for the effective restoration and functioning of the dry-stone walled vineyards on one hand, and construct performance-oriented design strategies to enable knowledge-based design processes on the other hand. Such methods are based on the use of the collected geospatial data, geoscientific analysis, and simulations, as well as iterative, multi-scalar design processes. Such approach was partially pursued in the aforementioned research and recently discussed in-depth in the context of 'ecological prototypes', which constitute a particular type of Green Constructions. The Lamole 
terraced vineyards are considered to provide diverse ecosystem services and help increase biodiversity. The conducted surveys will contribute to establishing the Key Performance Indicators for the design of ecological prototypes, aiming at the construction of multi-scale computational tools and methods, resulting in the definition of the design decision support system (Hensel \& Sørensen, 2019; Sunguroğlu Hensel, 2020).

In the upcoming years, understanding the contribution of plants from the multi-scalar perspective will be addressed. A study on the vine plant physiology in a wide time series would allow for the qualitative evaluation of the benefits that historical terraced vineyards provide for the resulting product. The role of the mosaicked land-use patterns visible in the historic terraced vineyards is believed to play an important role in creating diverse ecosystems, incorporating water collecting crevasses and forests surrounding the vineyards. Future activities will utilize the photogrammetric data collected during the past surveys and blend it with the airborne LiDAR data, acquired in July 2020 , to encompass the wide range of scales.

The thermographic study previously conducted on the Grospoli I vineyard presented temperature distribution patterns induced by the dry-stone walls on the vine rows. Limited time resolution, as well as spatial resolution of the resulting TIR point cloud was also mentioned. Preliminary results are promising, showing a strong correlation between the control measurements and the acquired data. Low-cost, integrated platform allowed for longer flight times, not constrained by the limited power supply of the TIR sensor used in the 2017 survey. Relatively short recharging intervals allowed to complete five UAV acquisitions of the whole Grospoli II vineyard in a day, extending the temporal scale of the acquired data. On the other hand, the quality of the resulting point cloud in both RGB and TIR spectrum is being currently evaluated. This study was conducted in the Grospoli II vineyard (Fig. 2), as well as in the Castello vineyard (Fig. 3).

A particular property of the Castello vineyard is that both the terraced and non-terraced parts are present in one vineyard. Photogrammetric data was collected in September 2020 with multiple UAVs flights with combined RGB and TIR acquisition, to include both terraced and non-terraced parts in the survey, documenting their geometry and thermal behaviour. Datasets collected in the different vineyards throughout the years are currently being analysed: it is still to be discovered to which degree such diverse data can be compared and effectively used to help understanding the environmental role of the historic dry-stone walls in the terraced vineyards. On one hand, a systematically constructed methodology would suggest that such direct comparison should be possible. On the other hand, the Grospoli vineyards and Castello are located on different altitudes and are facing different directions. Understanding how the different factors influence the role and functioning of the dry-wall terraces poses a challenge, but the understanding of the interdependencies would be an important step forward, allowing to construct an effective decision-support system.

In future research, given the availability of airborne LiDAR data of the entire valley (Fig. 6), photogrammetric and thermographic measurements taken in different vineyards will be correlated spatially. Also, the availability of data obtained from classification methodologies of the point cloud, such as LiDAR-based terrain and tree canopy models, will be used in the geospatial simulations to understand the significance of the historical terraced vineyards on the territorial scale.
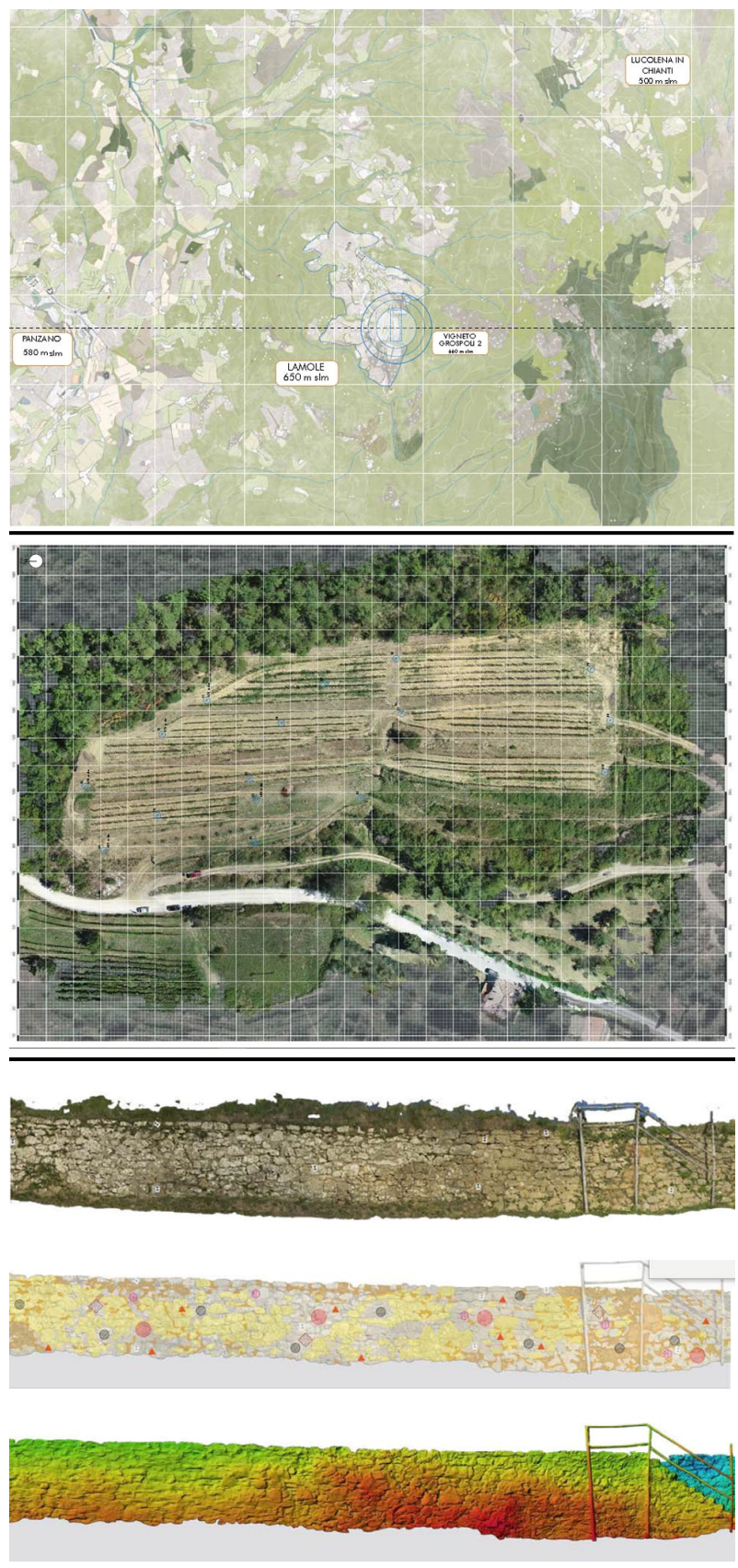

Figure 5: Example of multi-scalar analysis applied to the terraced landscape of Lamole (Gambini, Nassi, \& Tesi, 2020). Starting from the top: terrestrial scale analysis of the mosaicked land use, based on the regional GIS data; Grospoli II vineyard marked in blue. In the centre: orthophoto from the 3D model produced by UAV photogrammetry of the Grospoli II vineyard (GSD $1.5 \mathrm{~cm} / \mathrm{px}$ ). Last three illustrations: orthophoto of a single dry-stone wall (GSD $1 \mathrm{~mm} / \mathrm{px}$ ), characterized by bulging problems, thematic map of the material degradation, and DEM model to identify bulging and related structural problems.

These data represent a considerable source of information that can be used for several applications in different research field, as for example geological monitoring, for the study of induced-landslides due to terraces abandonment with innovative sensors (Mucchi et 
al., 2020). Moreover, the application of multispectral and hyperspectral sensors, active in other ranges of the electromagnetic spectrum, is considered in the near future, enabling the calculation of biophysical vegetation indices, which is widely applied in precision agriculture (Adão et al., 2017; Pastonchi, Di Gennaro, Toscano, \& Matese, 2020).

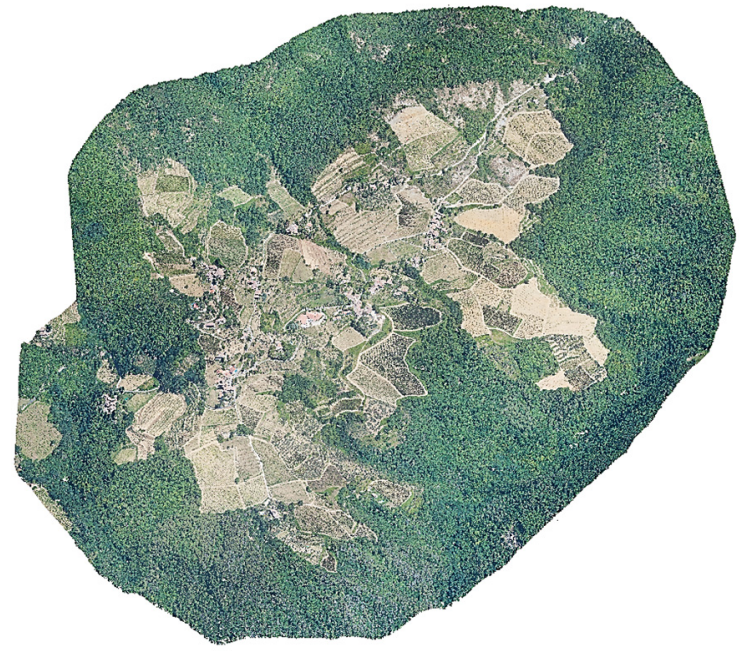

Figure 6: The airborne LiDAR data (point cloud) covering Lamole and the surrounding valley. All vineyards in the area are included in this dataset. Multiple returns acquired by the LiDAR sensor allow to properly model both tree canopies (DSM) and the underlying landform (DTM). This dataset is considered to help understanding the water regimes and related ecosystem functions. Complex relations between the form of the valley partially covered with forests and the terraced vineyards result

in the mosaicked land use pattern of small vineyards, interwoven with the water-diverting crevasses.

\section{Conclusions}

This contribution aims at presenting the research activities performed on terraced landscapes in Lamole.

Anthropic modification of the environment with terracing, as well as the recovery and conservation of traditional knowledge, has being increasingly recognized recently. Unique qualities of terraced landscapes, referred to as "Cultural landscapes" and "Heroic and historic vineyards" are acknowledged by UNESCO, FAO-GIAHS, and Italian governmental Bodies. "Art of dry-stone walling" refers to the knowledge related to construction and operation of the terraced vineyards and is considered as an Intangible Cultural Heritage of Humanity by UNESCO. Thus, terraced landscapes are clearly understood as carriers of social, cultural, and economical qualities.

The involvement of expertise from different research fields has converged over the years in Lamole. Peculiarities of the Chianti area and presence of wellestablished agricultural terraced systems resulted in Lamole being chosen as primary case study of the presented interdisciplinary research activities. The multidomain approach towards those unique landscape forms, allowed to study the impacts of such diffuse heritage under different levels. This, in turn uncovered new research directions that will be further addressed in future study cases in Tuscany, Italy, and worldwide.

In particular, the description of the evolution of the methodologies adopted for studying temperature variations induced by terraces and dry-stone walls in selected vineyards is reported. The first test on the field (in 2017) involved the use of UAV-mounted VIS and TIR sensors, for temperature evaluations of the entire vineyard. A suitable procedure for data extraction and the related information obtained have been studied. The promising results further led to increase the spatial and temporal resolution with experiments on the ground (2019) with thermal camera for the evaluation of surface temperatures of plants and walls, to finally combine the two methodologies for a multi-scalar approach in 2020. The currently available results and the research they have fostered, have been described in section 4.2. The data from the last surveys has currently being analyzed, although the trend of the future research has been mentioned in 4.3 section.

In the recent years, growing numbers of vineyards in Lamole have been captured photogrammetrically in both TIR and VIS ranges. Subsequent acquisitions of both historic and newly established vineyards will allow to monitor geometric changes and to address the questions of changing environmental conditions in the terraced vineyards. Inclusion of airborne LiDAR data and multispectral photogrammetric data in the future will allow to extend the scope of investigation.

\section{Acknowledgements}

Authors would like to acknowledge all the research group of the Geomatics for Environment and Conservation of Cultural Heritage Laboratory of the Department of Civil and Environmental Engineering at the University of Florence, directed and coordinated by Prof. Grazia Tucci for the constant involvement in Lamole surveys (data acquisition, processing and analysis); at the Department of Digital Architecture and Planning at Vienna University of Technology, Prof. Michael Hensel as well as Defne Sunguroglu Hensel for her numerous contributions foregrounding the prominent environmental role of the terraced vineyards; Mr. Paolo Socci, proprietor of Fattoria di Lamole, for his support, knowledge sharing and participation in all the activities. Special thanks go also to Filippo Fiaschi, DICEA flight operator for UAV flights. Finally, the authors wish to thank the students Sofia Gambini, Carolina Nassi, and Jessica Tesi, for their thesis work and for providing some of the image present in this contribution.

\section{References}

Adão, T., Hruška, J., Pádua, L., Bessa, J., Peres, E., Morais, R., \& Sousa, J. J. (2017). Hyperspectral imaging: A review on UAV-based sensors, data processing and applications for agriculture and forestry. Remote Sensing, 9(11). https://doi.org/10.3390/rs9111110

Agnoletti, M. (Ed.). (2013). Italian Historical Rural Landscapes. Environmental History (Vol. 1). Dordrecht: Springer Netherlands. https://doi.org/10.1007/978-94-007-5354-9 
Agnoletti, M., Conti, L., Frezza, L., Monti, M., \& Santoro, A. (2015). Features analysis of dry stone walls of Tuscany (Italy). Sustainability, 7(10), 13887-13903. https://doi.org/10.3390/su71013887

FAO-GIAHS (2002). Globally Important Agricultural Heritage Systems. Retrieved November 25, 2020, from http://www.fao.org/giahs/background/a-global-partnership/en/

Gambini, S., Nassi, C., \& Tesi, J. (2020). Aerial and terrestrial photogrammetry and GIS for multiscale reading of the terraced landscape of Lamole in Chianti. Master's Degree in Architecture, University of Florence. Tutor: Prof. G. Tucci, co-tutor: Prof. T. Matteini.

Hensel, M. U., \& Sørensen, S. S. (2019). Performance-oriented architecture and urban design. FormAkademisk Forskningstidsskrift for Design Og Designdidaktikk, 12(2). https://doi.org/10.7577/formakademisk.2963

Intergovernmental Committee. (2018). Decision of the Intergovernmental Committee: 13.COM 10.B.10. Retrieved November 25, 2020, from https://ich.unesco.org/en/decisions/13.COM/10.B.10

Inter-ministerial Decree. (2020). Safeguard of heroic and historical vineyards. Retrieved November 25, 2020, from https://www.politicheagricole.it/flex/cm/pages/ServeBLOB.php/L/IT/IDPagina/15621

Kelly, J., Kljun, N., Olsson, P. O., Mihai, L., Liljeblad, B., Weslien, P., Klemedtsson L., \& Eklundh, L. (2019). Challenges and best practices for deriving temperature data from an uncalibrated UAV thermal infrared camera. Remote Sensing, 11(5). https://doi.org/10.3390/rs11050567

Ministerial Decree (2018). Italian Ministerial Decree n. 6415 of 20 February 2018. Retrieved November 25, 2020, from https://www.reterurale.it/flex/cm/pages/ServeBLOB.php/L/IT/IDPagina/18073

Mucchi, L., Jayousi, S., Martinelli, A., Caputo, S., Intrieri, E., Gigli, G., Gracchi, T., Mugnai, F., Favalli, M., Fornaciai, A., \& Nannipieri, L. (2018). A Flexible Wireless Sensor Network Based on Ultra-Wide Band Technology for Ground Instability Monitoring. Sensors, 18, 2948. https://doi,org/10.3390/s18092948

Parisi, E. I., Suma, M., Güleç Korumaz, A., Rosina, E., \& Tucci, G. (2019). Aerial platforms (UAV) surveys in the VIS and TIR range. Applications on archaeology and agriculture. ISPRS Annals of the Photogrammetry, Remote Sensing and Spatial Information Sciences, 42(2/W11), 945-952. https://doi.org/10.5194/isprs-Archives-XLII-2-W11-9452019

Pastonchi, L., Di Gennaro, S. F., Toscano, P., \& Matese, A. (2020). Comparison between satellite and ground data with UAV-based information to analyse vineyard spatio-temporal variability. OENO One, 54(4), 919-934. https://doi.org/10.20870/oeno-one.2020.54.4.4028

Preti, F., Errico, A., Caruso, M., Dani, A., \& Guastini, E. (2018). Dry-stone wall terrace monitoring and modelling. Land Degradation and Development, 29(6), 1806-1818. https://doi.org/10.1002/ldr.2926

Preti, F., Guastini, E., Penna, D., Dani, A., Cassiani, G., Boaga, J., Deiana R., Romano N., Nasta P., Palladino M., Errico A., Giambastiani Y., Trucchi P., \& Tarolli, P. (2018). Conceptualization of Water Flow Pathways in Agricultural Terraced Landscapes. Land Degradation and Development, 29(3), 651-662. https://doi.org/10.1002/ldr.2764

Preti, F., Tarolli, P., Dani, A., Calligaro, S., \& Prosdocimi, M. (2013). LiDAR derived high resolution topography: the next challenge for the analysis of terraces stability and vineyard soil erosion. Journal of Agricultural Engineering, 44(2s). https://doi.org/10.4081/jae.2013.s2.e16

Sereni, E. (Ed.). (1991). Storia del paesaggio agrario italiano. Bari, Italia: Laterza. Retrieved November 25, 2020, from https://books.google.it/books?id=w6n-SQAACAAJ

Socci, P., Errico, A., Castelli, G., Penna, D., \& Preti, F., (2019). Terracing: From Agriculture to Multiple Ecosystem Services. In Oxford Research Encyclopedia of Environmental Science. https://doi.org/10.1093/acrefore/9780199389414.013.206

Sunguroğlu Hensel, D. (2020). Ecological prototypes: Initiating design innovation in green construction. Sustainability, 12(14). https://doi.org/10.3390/su12145865

Tarolli, P., Preti, F., \& Romano, N. (2014). Terraced landscapes: From an old best practice to a potential hazard for soil degradation due to land abandonment. Anthropocene, 6, 10-25. https://doi.org/10.1016/j.ancene.2014.03.002

Tarolli, P., So, G., Calligaro, S., Prosdocimi, M., Preti, F., \& Fontana, G. D. (2015). Vineyards in Terraced Landscapes: new opportunities from LiDAR data. Land Degradation \& Development, 102(26), 92-102. https://doi.org/10.1002/ldr.2311

Tucci, G., Parisi, E. I., Castelli, G., Errico, A., Corongiu, M., Sona, G., Viviani E., Bresci E., \& Preti, F. (2019). Multi-Sensor UAV Application for Thermal Analysis on a Dry-Stone Terraced Vineyard in Rural Tuscany Landscape. ISPRS International Journal of Geo-Information, 8(2), 87. https://doi.org/10.3390/ijgi8020087

UNESCO (1979). World Heritage List. Retrieved November 25, from https://whc.unesco.org/en/list/\&order=country

Varotto, M., Bonardi, L., \& Tarolli, P. (Eds.) (2019). World Terraced Landscapes: History, Environment, Quality of Life, 9. Cham: Springer International Publishing. https://doi.org/10.1007/978-3-319-96815-5 